\title{
Valoración visual de la calidad ambiental del área urbana de Querétaro, México: la compleja sencillez de valorar el entorno urbano ${ }^{1}$
}

\author{
Juan Hernández-Guerrero²
}

\begin{abstract}
RESUMEN
En diversos espacios urbanos latinoamericanos la evaluación de la calidad ambiental es costosa y los resultados son poco claros para la mayoría de las personas. De tal forma, se plantea el análisis de la calidad ambiental del área urbana del municipio de Querétaro, México (AUMQ), a partir de la propuesta de un índice de calidad ambiental urbana (ICAU) que parte de la generación de variables ambientales definidas mediante valoración visual del agua, aire y suelo en unidades censales. Se indaga la presencia de clústers espaciales que acentúan el deterioro de la calidad ambiental urbana (CAU). Los resultados mostraron que la CAU disminuye conforme los clústers se alejan del centro urbano, a la vez que las zonas prioritarias se asocian con las variables de suelo y aire. Se concluye con 27 variables ambientales inéditas para el AUMQ, los productos son actualizables y la metodología puede ser replicada en otros espacios urbanos.
\end{abstract}

Palabras clave: Calidad ambiental, Valoración visual, Área urbana, Clúster espacial.

\begin{abstract}
In several Latin American urban spaces, assessing environmental quality is costly and the results are unclear to most people. Given this, we performed an analysis of the environmental quality of the urban area of Querétaro, México (UAMQ or in spanish $A \cup M Q$ ). To this end, we developed an urban environmental quality index (UEQI or in spanish ICAU) that is based on a visual assessment, along census tracts, of the following environmental variables: water, air and soil. We investigated the presence of spatial clusters that accentuate the deterioration of urban environmental quality (UEQ or CAU in Spanish). Our results showed that the UEQ decreased in clusters as you move away from the urban center, while the priority areas are associated with the variables soil and air. We also present 27 unreleased environmental variables for $A \cup M Q$, whose results and methodology could be replicated for other urban spaces.
\end{abstract}

Key words: Environmental quality, Visual assessment, Urban areas, Spatial cluster.

\footnotetext{
1 El presente estudio forma parte del proyecto de investigación titulado "Precariedad habitacional y deterioro ambiental en el periurbano de la ciudad de Querétaro", mismo que contó con financiamiento FOFI-UAQ (20101177). Asimismo se otorgan especiales agradecimientos a Alma Angélica Navarrete Carrillo, Yaret Guerrero Rodríguez, Diana Angélica Benítez Pulido y Lorena García Estrada por la coordinación de equipos de trabajo, manejo de SIG y
}

elaboración de bases de datos. Al Dr. Antonio Vieyra y Dr. Luis Enrique Granados por sus importantes contribuciones. Artículo recibido el 3 de octubre de 2014, aceptado el 5 de diciembre de 2014 y corregido el 23 de enero de 2015.

2 Facultad de Ciencias Naturales, Universidad Autónoma de Querétaro (México).

E-mail: juan.hernandez@uaq.mx 
La relación sistémica entre hombre y naturaleza ha sido desde siempre la esencia del espacio geográfico y de la comprensión evolutiva de los territorios (Santos, 2007). Para Bertrand y Bertrand (2007), la dimensión territorial otorga la especificidad a la cuestión ambiental, a la vez que la función espacio-tiempo-escala permite asociar el grado de impacto de las actividades con los efectos negativos de estas sobre el ambiente. En este sentido, Heynen (2006) y Grimmond (2007) mencionan que la especificidad de los problemas ambientales se acentúa en áreas urbanas por la velocidad con que se dispone y degradan los recursos naturales.

Se distingue dentro de las áreas urbanas espacios diferenciados por un mercado ambiental en el que los recursos naturales se manejan como un bien de consumo proporcional a los elementos de capital fijo de producción (industrias, vialidades) y a los del fondo de consumo (viviendas, áreas recreativas); ambos casos asumen un valor de cambio que determina su distribución (Fuentes et al., 2011: 7). Es por estas razones que el poder adquisitivo de los diferentes grupos sociales en áreas urbanas promueve un mercado ambiental heterogéneo que se convierte en una condición de distribución espacial según las capacidades de los estratos poblacionales (Harvey, 1997; Hernández \& Vieyra, 2012).

En este sentido, se favorecen procesos de segregación socioambiental, en la medida que pobladores de bajos ingresos son excluidos respecto a las características del mercado ambiental. Pero ese fenómeno de segregación no solo involucra una situación social o espacial, sino también estructural que se observa en la deficiente calidad ambiental urbana, pues los grupos en esta condición suelen ser incapaces (social, económico y político) para transformar en externalidades los elementos nocivos y costos ambientales, a la vez que reciben de forma exagerada los efectos de la contaminación, o bien, son restringidos para ocupar sitios ambientalmente menos degradados (Romero et al., 2011: 56).

La calidad ambiental urbana involucra factores socioambientales interconectados (poblaciones, red vial, edificaciones, áreas verdes, calidad del aire y agua) que influyen de forma negativa o positiva sobre la vida de las personas (Nichol \& Wong, 2005; citado por Santana et al., 2010: 78). En este contexto, el proceso de segregación socioambiental abre la brecha entre calidad ambiental del entorno urbano y calidad de vida; se suele asociar el nivel socioeconómico como criterio de selección de calidad ambiental. Con ello, se formulan valoraciones ambientales diferenciadas que se complejizan debido a la reducción de la distancia física entre grupos socioeconómicos que, regularmente se encuentran confinados y delimitados en una misma zona (barrios, distritos o manzanas urbanas), adoptando nuevos símbolos y significados que modifican constantemente el entorno urbano inmediato exponiendo sensaciones de detrimento, desagrado e insatisfacción urbano-ambiental (Pacione, 2003; Gomes, 2010; Fuentes et al., 2011; Briceño et al., 2011).

En ciudades de Latinoamérica, la calidad ambiental urbana es el reflejo de las formas de apropiación de la naturaleza en dependencia de la construcción, ocupación y evolución de las propias áreas urbanas (Schuster \& Edelman, 2003). Hasta la década de los setenta, el proceso de urbanización estaba relacionado con importantes eventos de crecimiento demográfico, migración rural-urbana, concentración poblacional e industrialización sustitutiva de importaciones. Esos escenarios no solo establecieron el crecimiento de grandes ciudades y áreas metropolitanas, sino que intensificaron problemáticas e inequidades sociales, económicas, políticas y ambientales que fomentaron el desarrollo de nuevas urbes y un modelo urbano fragmentado inmerso en la inadecuada apropiación de la naturaleza (Bähr y Borsdorf, 2005; Bolay et al., 2005; Azócar et al., 2008; Vázquez y Salgado, 2009).

Ese modelo urbano fragmentado juega un papel importante en los procesos de degradación ambiental en ciudades de tamaño intermedio, ya que a diferencia de las grandes aglomeraciones donde los problemas ambientales son trascendentes y de gran extensión, en ciudades intermedias se incrementan los problemas ambientales a consecuencia de los elevados niveles de crecimiento actual (concentración poblacional y procesos productivos y culturales), situación que se relaciona con el objetivo de ser competitivas, 
y que en correspondencia con sus áreas de influencia, generan economías de concentración o clústers territoriales (Balbo et al., 2003; citado por Azócar et al., 2008: 104). Además son acompañadas de segregación socioambiental en proporción con la rapidez y dinámica en el aumento de necesidades y disminución de oportunidades, o bien, por transformaciones derivadas del proceso de transición rural-urbana, mercado inmobiliario con pocas restricciones y la constante reconfiguración territorial. Bajo estos factores, se acentúan nuevas formas de urbanización y problemáticas urbano-ambientales, generando espacios polarizados de evidente degradación ambiental, misma que suele ser irreversible y con efectos negativos en sitios que hasta hace unos años eran beneficiados por condiciones ambientales favorables (De Vries et al., 2001; Fuentes et al., 2011).

Estudios científicos en ciudades de Chile, Venezuela, Cuba y Brasil utilizan técnicas de valoración visual para analizar la calidad ambiental urbana. Todos ellos con objetivos y procedimientos similares (contraste visual, dominancia visual, extensión de la escena y estética de la imagen urbana) a fin de identificar propiedades subjetivas, gráficas y cognoscitivas (Guerra, 2001; Briceño \& Gil, 2003; Cabreiro y Rodríguez, 2010; Santos \& Pinto, 2010; Fuentes et al., 2011). Esos trabajos dan cuenta de construcciones propositivas para la planeación y calidad de vida urbana, pero no logran establecer una valoración integral para la totalidad urbana, pues en la mayoría, la escala de estudio ocasiona análisis parcial debido a evaluaciones específicas, sean casos individuales o comparativos. Asimismo, la propia subjetividad con que se valora el entorno urbano suele mostrar interpretaciones muy heterogéneas, ocasionado por las diferentes percepciones $y / o$ el rango de valoración, con ello se abre la brecha entre lo que se observa, se percibe y se juzga.

En el caso de México existe una notoria ausencia de trabajos sobre valoración visual de la calidad ambiental en áreas urbanas, no así en espacios rurales (Montoya et al., 2003), aunque los resultados son similares a los ya comentados. A pesar de esa carencia, se distinguen espacios heterogéneos con diferente calidad ambiental en ciudades de México. De esta forma, es que surge el planteamiento de valorar visualmente la calidad ambiental del área urbana de Querétaro (AUMQ), una urbe de tamaño intermedio ${ }^{3}$ que desde la década de los noventa ha experimentado importantes transformaciones territoriales, mismas que han derivado en la formación de espacios ambientalmente diferenciados. Para responder a ese objetivo, a la vez de contribuir con una interpretación sencilla mediante valoraciones subjetivas, se desarrolló un índice de calidad ambiental urbana utilizando valoración visual, pero a esta última se asignaron elementos cuantitativos correspondientes a la repetición de elementos perjudiciales en el entorno inmediato de unidades censales urbanas. Así se pretende contribuir de manera sencilla a evaluar variables urbano-ambientales que por su naturaleza y dinamismo son complejas. Finalmente con el uso de Sistemas de Información Geográfica se desarrollaron clústers espaciales para analizar la totalidad del área urbana.

Este trabajo señala como punto de partida que debido a la dinámica urbana del municipio de Querétaro, la calidad ambiental pudiera disminuir conforme se aleja del centro urbano, ya que en la periferia es donde se localizan sectores con un mayor grado de fragmentación social, económica y residencial, al mismo tiempo se podrían identificar clústers espaciales donde se enfatizarían zonas prioritarias de atención socioambiental. Además, la cuantificación de elementos repetitivos (perjudiciales o benéficos) puede otorgar mayor sencillez a la interpretación de variables ambientales. De forma específica, se plantean las siguientes preguntas: 1) ¿Qué nivel de calidad ambiental urbana presenta el AUMQ?; 2) ¿Qué sector de la ciudad presenta las diferencias más notorias en relación a la calidad ambiental urbana; 3) ¿Cuáles son las zonas prioritarias de atención ambiental?

\section{Área de estudio}

El estudio se desarrolla en el área urbana del municipio de Querétaro (AUMQ), una zona de trascendencia histórica, cultural y

\footnotetext{
3 En México, una ciudad intermedia está definida por un núcleo poblacional en un rango de 100.000 y 999.999 habitantes.
} 
económica a nivel nacional y regional. Se localiza al sur-este del estado de Querétaro (Figura $\mathrm{N}^{\circ} 1$ ), representa el principal centro poblacional y político-administrativo del estado. Constituye una sección importante de la ciudad media de Querétaro, al año 2010 el AUMQ es integrada por el $85 \%$ de la población y el $75 \%$ de la superficie de la ciudad, 703.699 habitantes y $122,44 \mathrm{~km}^{2}$ respectivamente. El resto de la ciudad refiere a secciones urbanas del municipio de Corregidora y El Marqués que no fueron consideradas en el proyecto del cual se desprende este documento.

Después de la segunda mitad del siglo XX, el AUMQ presenció un notorio incremento poblacional y de expansión urbana (Figura $N^{\circ}$ 2) que derivaron en la transformación del territorio con efectos negativos sobre el ambiente. La intensidad de estos procesos se asocia, entre otros, con el auge de la industria de los años setenta y el desarrollo de parques industriales en los años ochenta (García, 1986; Icazuriaga, 1994; González, 2012). El Programa de las Naciones Unidas para el Medio Ambiente (PNUMA, 2008) señala que en esos años se promovieron amenazas hacia el ambiente (deforestación, ocupación de ríos y cuerpos de agua y deterioro de recursos naturales) producto de la intensa ocupación de espacios no aptos para el desarrollo urbano, principalmente la construcción habitacional.

Entre las décadas de 1990 y 2005 el desarrollo habitacional aumentó $28,33 \%$ (5\% a nivel nacional en ese periodo), a la vez que fue acompañada de la respectiva cobertura y equipamiento urbano. De forma paralela, se intensificó el incremento de problemáticas ambientales en agua, suelo y aire, lo que trajo consigo una notoria presión sobre los recursos naturales y disminución de la calidad ambiental en el AUMQ (PNUMA, 2008).

El PNUMA (2008) y el Consejo de Ciencia y Tecnología del Estado de Querétaro (CONCYTEQ, 2007) exponen que la calidad del ambiente del AUMQ no es la ideal debido a diversas presiones; dinámica del mercado del suelo, sobrepoblación, inadecuada planeación del territorio, emisiones industriales y vehiculares, deposición de residuos sólidos, sobreexplotación de acuíferos y uso y manejo

Figura $\mathrm{N}^{\circ} 1$

Localización del área urbana del municipio de Querétaro
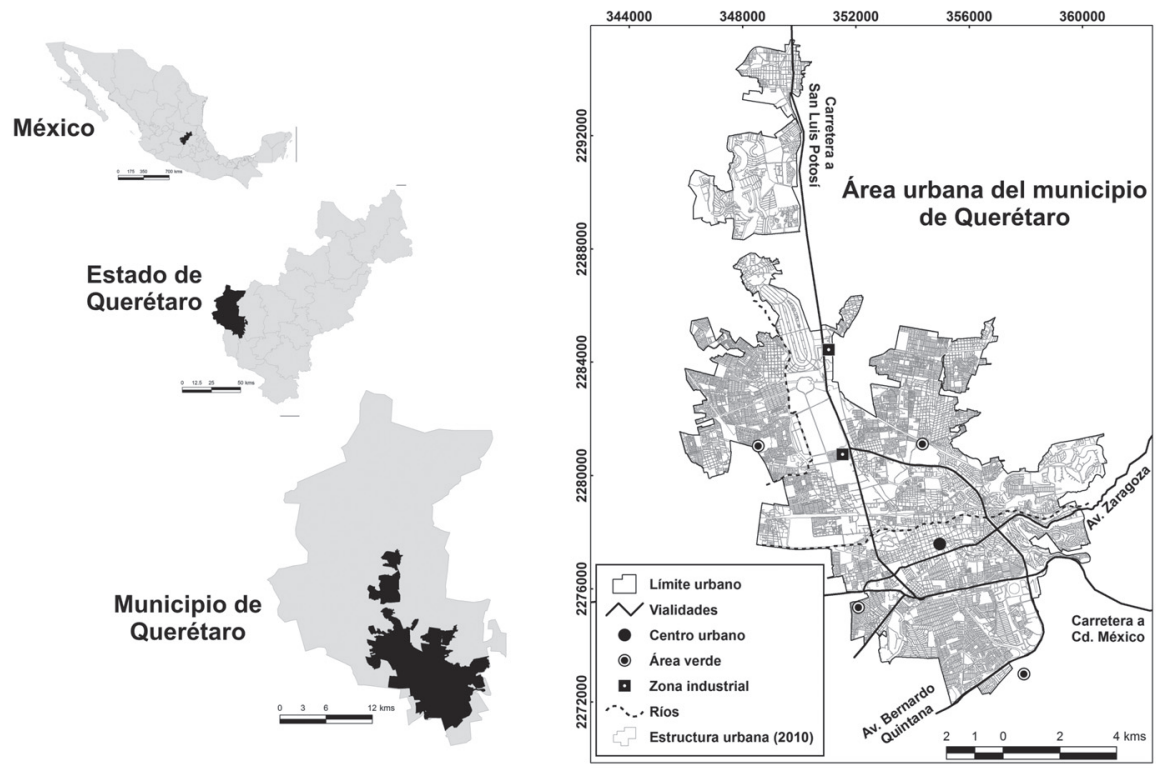

Fuente: Elaboración propia en base a INEGI (2010). 
Figura $\mathrm{N}^{\circ} 2$

Escenarios de expansión física del área urbana del municipio de Querétaro, 1950-2010

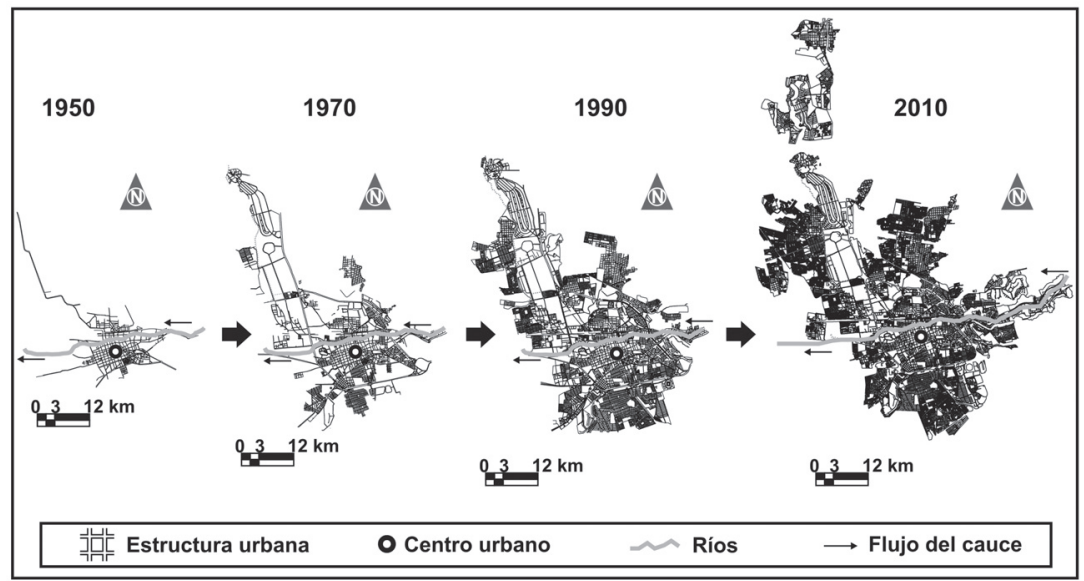

Fuente: Elaboración propia en base a INEGI (2010).

inadecuado de los recursos naturales. Al respecto, los discursos oficiales son contradictorios, el plan de desarrollo urbano municipal de Querétaro (2012-2015) menciona que existen $9 \mathrm{~m}^{2}$ de áreas verdes por habitantes, pero el CONCYTEQ (2007) señala que a nivel municipal la cantidad es de $6 \mathrm{~m}^{2}$ y para el AUMQ es de apenas $2 \mathrm{~m}^{2}$. La Comisión Estatal de Aguas (CEA) en discursos publicitarios señala que el suministro de agua a las residencias es de excelente calidad, pero por otro lado, es evidente el déficit de agua por la sobreexplotación de acuíferos. También, en el AUMQ se genera un promedio de 900 toneladas de basura al día de las 1.300 que se generan en todo el estado. Por último, la red de monitoreo de calidad del aire (constituida por cuatro estaciones fijas y dos móviles) de manera regular registra buena calidad del aire (según las normas oficiales mexicanas), a pesar del evidente aumento de fuentes contaminantes (móviles y fijas) y los mínimos controles de emisiones.

\section{Materiales y métodos}

Con base en las preguntas clave y el objetivo planteado en este estudio, la metodología da cuenta de la elaboración de una propuesta de un índice de la calidad ambiental urbana a fin de identificar zonas prioritarias de atención ambiental en el AUMQ. A fin de lograr los resultados esperados, se utilizaron técnicas estadísticas y un Sistema de Información Geográfica (SIG), así como la inclusión de programas especializados: ArcGis, SPSS, Photoshop y CorelDraw. De manera específica, el proceso metodológico da cuenta de tres fases que se describen a continuación.

Primera fase. Reconocimiento de la unidad de análisis.

El presente estudio analizó la totalidad urbana de Querétaro disgregada en unidades censales conocidas como Área Geoestadística Básica (AGEB). La AGEB es una división geográfica mínima con fines estadísticos y censales empleada por el Instituto Nacional de Geografía y Estadística (INEGI). En este contexto, se utilizaron 304 AGEB, mismas que cubren por completo el área urbana. Esas unidades fueron obtenidas en formato vectorial e incluidas en el SIG para su posterior representación cartográfica.

Segunda fase. Elaboración del índice de calidad ambiental urbana

La elaboración de la propuesta del índice de calidad ambiental urbana (ICAU) parte de la valoración visual del entorno inmediato de las AGEB del AUMQ. El índice está constituido por tres grupos temáticos; agua, suelo y aire. Se utilizaron componentes visuales como color, escala y dimensión, equivalen- 
tes al contraste visual, dominancia visual y extensión de la escena (Smardon et al., 1986; Briceño et al., 2011). De forma específica, se emplearon trabajos que ayudaron a definir, caracterizar, describir y valorar variables ambientales inéditas para el AUMQ; el grupo temático del agua fue construido con aportes de Montoya et al. (2003), Arriaza et al. (2003), Lyions et al. (1995) y Muñoz et al. (2006). En la temática del suelo se destacan los aportes de Chung et al. (2012), Milroy et al. (2001) y Briceño et al. (2011) y para el grupo del aire se consideró el trabajo de Yuan et al. (2002) y Romero et al. (2010). Además, se incluyeron estrategias de recolección de información de Briceño et al. (2011), Montoya et al. (2003), Briceño y Gil (2003) y Lyions et al. (1995).

El proceso de obtención de información para generar el ICAU resultó del levantamiento de cuestionarios. Se inició con la selección de 25 AGEB representativos a lo largo del AUMQ. En esos AGEB se realizaron recorridos exploratorios y se levantaron 50 cuestionarios piloto (teniendo en cuenta grupos temáticos con variables para agua, suelo y aire) con 35 variables ambientales.

El levantamiento de los cuestionarios se llevó a cabo con recorridos circulares (dirección de las manecillas del reloj) a fin de valorar visualmente toda el AGEB; el punto de salida y llegada fue el centro de la propia unidad de análisis. En el transcurso del recorrido se dispusieron de puntos de observación. Cabe señalar que los recorridos se efectuaron por personas no residentes a las AGEB para evitar sesgos en la valoración. Los participantes, mayores de 18 años, recibieron capacitación previa y fueron seleccionados de manera individual debido a sus conocimientos básicos sobre análisis visual del paisaje.

El resultado del cuestionario piloto permitió obtener una primera valoración visual de la calidad ambiental urbana, así como la determinación de 27 variables (agrupadas en los temas de agua, suelo y aire) producto de la discriminación de 8 variables ambientales, que aplicando correlación de Kendall no presentaron correlación significativa (las variables discriminadas fueron de la temática de agua con valores entre: tau $=0.1022358$ y tau=0.3265847). Es así que se definieron los criterios del cuestionario final (desde este momento se nombrará cuestionario); descripción de variables ambientales, definición de rangos y dominancia visual de la variable (Cuadro $N^{\circ} 1, N^{\circ} 2$ y $N^{\circ} 3$ ). Cabe señalar que la dominancia visual resulta del porcentaje de la cuantificación o cualificación de la variable en el entorno de cada AGEB.

Cuadro $\mathrm{N}^{\circ} 1$

Variables ambientales en la temática del agua (A) utilizadas en el ICAU, 2013

\begin{tabular}{|c|c|c|}
\hline Variable & \begin{tabular}{|c} 
Descriptor de la calidad ambien- \\
tal
\end{tabular} & Forma de registro \\
\hline $\begin{array}{l}\text { Elementos } \\
\text { hídricos: Ríos, } \\
\text { arroyos, canales y } \\
\text { cuerpos de agua }\end{array}$ & $\begin{array}{l}\text { Presencia de agua; Indicativo de } \\
\text { vegetación; Atractivo turístico; } \\
\text { Recreación. }\end{array}$ & $\begin{array}{l}\text { Se asigna mayor calidad ambiental a uni- } \\
\text { dades de análisis con mayor cantidad de } \\
\text { elementos hídricos, independiente de la } \\
\text { dominancia y estado del elemento. }\end{array}$ \\
\hline Fugas de agua & $\begin{array}{l}\text { Desperdicio de agua; Ausencia } \\
\text { o insuficiente mantenimiento } \\
\text { hidráulico; Insuficiencia de edu- } \\
\text { cación y consciencia ambiental; } \\
\text { efectos negativos en el suminis- } \\
\text { tro de agua potable }\end{array}$ & $\begin{array}{l}\text { Se valora con mayor calidad ambiental a la } \\
\text { menor cantidad de fugas de agua en la vía } \\
\text { pública. Se cuantificaron aquellas fugas de } \\
\text { agua observadas fuera de las viviendas. }\end{array}$ \\
\hline
\end{tabular}




\begin{tabular}{|c|c|c|}
\hline Variable & $\begin{array}{c}\text { Descriptor de la calidad ambien- } \\
\text { tal }\end{array}$ & Forma de registro \\
\hline $\begin{array}{l}\text { Servicios de } \\
\text { autolavado }\end{array}$ & $\begin{array}{l}\text { Consumo excesivo y desperdi- } \\
\text { cio de agua; Residuos tóxicos al } \\
\text { drenaje. }\end{array}$ & $\begin{array}{l}\text { La mayor calidad es indicada por la menor } \\
\text { cantidad de servicios de autolavado. Este } \\
\text { valor es independiente del tamaño del ser- } \\
\text { vicio (empresa). }\end{array}$ \\
\hline $\begin{array}{l}\text { Alcantarillas } \\
\text { o bocas de } \\
\text { tormenta }\end{array}$ & $\begin{array}{l}\text { Infraestructura hidráulica; Con- } \\
\text { trol de inundaciones; Sanidad; } \\
\text { Captación de agua de lluvia. }\end{array}$ & $\begin{array}{l}\text { Se asigna mayor calidad ambiental a mayor } \\
\text { cantidad de alcantarillas. No se incluyeron } \\
\text { registros del drenaje, solo aquellos elemen- } \\
\text { tos que previenen inundaciones o enchar- } \\
\text { camientos. }\end{array}$ \\
\hline $\begin{array}{l}\text { Color del agua } \\
\text { de ríos, arroyos, } \\
\text { canales y cuerpos } \\
\text { de agua }\end{array}$ & $\begin{array}{l}\text { El agua en su estado puro debe } \\
\text { ser incolora. En el área urbana } \\
\text { se identificó agua transparente, } \\
\text { pero también se visualizaron } \\
\text { espumas, aceites, y colores obs- } \\
\text { curos indicativos de descargas } \\
\text { residuales urbanas. }\end{array}$ & $\begin{array}{l}\text { El color se eligió por la dominancia o par- } \\
\text { cialidad }(40 \%) \text {. En primer lugar se asigna } \\
\text { mayor calidad al agua clara (transparente), } \\
\text { en segundo lugar colores amarillos por la } \\
\text { presencia de tierra y residuos orgánicos, } \\
\text { en tercer lugar el color blanco por la pre- } \\
\text { sencia de espumas (detergente), en cuarto } \\
\text { lugar el color café claro por la presencia } \\
\text { de aceites y en quinto lugar el color café } \\
\text { obscuro y negro debido a residuos fecales } \\
\text { y grasas. }\end{array}$ \\
\hline $\begin{array}{l}\text { Olor del agua } \\
\text { de ríos, arroyos, } \\
\text { canales y cuerpos } \\
\text { de agua }\end{array}$ & $\begin{array}{l}\text { El agua en su estado puro es } \\
\text { inodora. En el área urbana se } \\
\text { identificaron olores intensos que } \\
\text { despiden los elementos hídricos. } \\
\text { Esto es indicativo de descargas } \\
\text { residuales urbanas, insuficiencia } \\
\text { de mantenimiento o mal uso de } \\
\text { los elementos hídricos. }\end{array}$ & $\begin{array}{l}\text { Se valoró con mayor calidad a los elemen- } \\
\text { tos hídricos que no despidieron olores en } \\
\text { un rango de } 5 \text { metros de distancia, mien- } \\
\text { tras que la menor calidad ambiental se } \\
\text { presentó en los elementos que despidieron } \\
\text { malos olores a } 25 \text { metros de distancia del } \\
\text { elemento hídrico. }\end{array}$ \\
\hline $\begin{array}{l}\text { Presencia de } \\
\text { basura en el agua } \\
\text { de ríos, arroyos, } \\
\text { canales y cuerpos } \\
\text { de agua }\end{array}$ & $\begin{array}{l}\text { Inadecuado mantenimiento; In- } \\
\text { salubridad; }\end{array}$ & $\begin{array}{l}\text { Se valoró con mayor calidad a los ele- } \\
\text { mentos hídricos sin presencia de basura, } \\
\text { mientras la menor calidad ambiental refie- } \\
\text { re a más de } 50 \text { residuos sobre la lámina de } \\
\text { agua. Este dato refiere al promedio de las } \\
\text { observaciones. Tres puntos de observación } \\
\text { con duración de } 7 \text { minutos en cada ele- } \\
\text { mento hídrico. }\end{array}$ \\
\hline $\begin{array}{l}\text { Fauna nociva } \\
\text { en ríos, arroyos, } \\
\text { canales y cuerpos } \\
\text { de agua }\end{array}$ & $\begin{array}{l}\text { Insalubridad; Susceptibilidad so- } \\
\text { cioambiental; Seguridad vial. }\end{array}$ & $\begin{array}{l}\text { Tres puntos de observación con duración } \\
\text { de } 7 \text { minutos en cada elemento hídrico. Se } \\
\text { valoró con mayor calidad a los elementos } \\
\text { hídricos sin presencia de fauna nociva. La } \\
\text { menor calidad fue señalada por más de } 10 \\
\text { especies independiente de la dominancia } \\
\text { de la especie. Este dato refiere al prome- } \\
\text { dio de las observaciones en la zona limí- } \\
\text { trofe de los elementos hídricos. }\end{array}$ \\
\hline
\end{tabular}

Fuente: Elaboración propia en base a los resultados del cuestionario piloto sobre calidad ambiental urbana. 
Cuadro $\mathrm{N}^{\circ} 2$

Variables ambientales en la temática del suelo (B) utilizadas en el ICAU, 2013

\begin{tabular}{|c|c|c|}
\hline Variable & Descriptor de la variable & Forma del rango de registro \\
\hline $\begin{array}{l}\text { hte } \\
\text { hinante }\end{array}$ & $\begin{array}{l}\text { A menor pendiente mayor depó- } \\
\text { sitos de basura y propensión a } \\
\text { inundaciones. A mayor pendiente } \\
\text { susceptibilidad de deslizamientos y } \\
\text { mayor descarga de emisiones con- } \\
\text { taminantes por vehículos. }\end{array}$ & $\begin{array}{l}\text { Se asigna mayor calidad a unidades de aná- } \\
\text { lisis con pendiente dominante menor al } 5 \% \\
\text { y menor calidad en aquellas unidades con } \\
\text { pendiente dominante mayor al } 25 \% \text {. }\end{array}$ \\
\hline $\begin{array}{l}\text { Vegetación } \\
\text { arbórea }\end{array}$ & $\begin{array}{l}\text { Regulación térmica e hídrica; re- } \\
\text { ducción de contaminación atmos- } \\
\text { férica; Generación de biodiversi- } \\
\text { dad; Calidad de vida }\end{array}$ & $\begin{array}{l}\text { Se valora con mayor calidad ambiental a las } \\
\text { unidades de análisis que contabilizaron ma- } \\
\text { yor cantidad de árboles presentes en la vía } \\
\text { pública ( } 40 \text { árboles). Para ser considerado } \\
\text { debe ser }=>2 \text { metros de altura }\end{array}$ \\
\hline $\begin{array}{l}\text { Depósito de } \\
\text { basura en las } \\
\text { calles (legal) }\end{array}$ & $\begin{array}{l}\text { Limpieza; salubridad; consciencia } \\
\text { ambiental; mantenimiento urbano; } \\
\text { acciones de reciclaje }\end{array}$ & $\begin{array}{l}\text { La mayor calidad es indicada por la mayor } \\
\text { cantidad de depósitos de basura }(>20) \text {. Este } \\
\text { valor involucra cualquier tipo de depósito, } \\
\text { independiente de su dominancia. }\end{array}$ \\
\hline $\begin{array}{l}\text { Depósito de } \\
\text { basura en las } \\
\text { calles (ilegal) }\end{array}$ & $\begin{array}{l}\text { Incremento de metano, óxido nitro- } \\
\text { so y óxido de carbono; inadecuado } \\
\text { mantenimiento urbano; insalubri- } \\
\text { dad; }\end{array}$ & $\begin{array}{l}\text { Se asigna mayor calidad ambiental a la } \\
\text { ausencia de depósitos ilegales de basura. } \\
\text { Mientras que la menor calidad está dada por } \\
\text { más de } 4 \text { depósitos. }\end{array}$ \\
\hline s y & $\begin{array}{l}\text { Valor estético; salubridad; activida- } \\
\text { des recreativas; regulación térmica; } \\
\text { captación de agua de Iluvia; Con- } \\
\text { centración y generación de biodi- } \\
\text { versidad. }\end{array}$ & $\begin{array}{l}\text { Se valora con mayor calidad a las unidades } \\
\text { de análisis que presenten más de } 4 \text { parques } \\
\text { y/o jardines. Este registro no difiere por ele- } \\
\text { mento dominante. }\end{array}$ \\
\hline $\begin{array}{l}\text { del } \\
\text { ano }\end{array}$ & $\begin{array}{l}\text { Atracción paisajística; dirección de } \\
\text { la morfología urbana; funciones y } \\
\text { servicios. }\end{array}$ & $\begin{array}{l}\text { Se valoró con mayor calidad a las áreas ver- } \\
\text { des por su función en la regulación hídrica y } \\
\text { térmica, así como la concentración de fauna } \\
\text { y vegetación. Por su parte, la menor calidad } \\
\text { está dada por la cobertura industrial debido } \\
\text { a sus efectos agrestes al entorno inmediato. } \\
\text { La cobertura responde a la dominancia vi- } \\
\text { sual }(60 \%) \text {. }\end{array}$ \\
\hline $\begin{array}{l}\text { Vegetación } \\
\text { arbórea } \\
\text { dañada }\end{array}$ & $\begin{array}{l}\text { Contaminación; insalubridad; re- } \\
\text { ducción de oxígeno; Disminución } \\
\text { de la regulación hídrica y térmica. }\end{array}$ & $\begin{array}{l}\text { Se asignó mayor calidad ambiental a la au- } \\
\text { sencia de árboles dañados, mientras que la } \\
\text { menor calidad refiere a un número mayor } \\
\text { de } 36 \text { árboles con algún signo de daño en su } \\
\text { estructura. Los daños refieren a árboles des- } \\
\text { cortezados, presencia de manchas negras, } \\
\text { quemados, con plaga, por un uso inapropia- } \\
\text { do (carteles u objetos insertados) o restos de } \\
\text { hollín en sus hojas. }\end{array}$ \\
\hline $\begin{array}{l}\text { Condición de } \\
\text { las calles }\end{array}$ & $\begin{array}{l}\text { Tránsito peatonal y automovilístico; } \\
\text { Seguridad vial. }\end{array}$ & $\begin{array}{l}\text { Se valoró con mayor calidad a la domi- } \\
\text { nancia de calles en buen estado (100\%). El } \\
\text { valor más alto refiere a calles con banquetas } \\
\text { amplias, luz pública; señalamientos; rampas } \\
\text { para discapacitados y ausencia de elementos } \\
\text { peligrosos (cables de energía, socavón u ob- } \\
\text { jetos punzocortantes). }\end{array}$ \\
\hline
\end{tabular}




\begin{tabular}{|c|c|c|}
\hline Variable & Descriptor de la variable & Forma del rango de registro \\
\hline $\begin{array}{l}\text { Funcionalidad } \\
\text { de las calles }\end{array}$ & $\begin{array}{l}\text { Seguridad vial; Tránsito peatonal y } \\
\text { automovilístico. Funciones a servi- } \\
\text { cios de emergencia. }\end{array}$ & $\begin{array}{l}\text { La mayor calidad se asignó a las calles que } \\
\text { no presentaron socavones y que tuvieran sa- } \\
\text { lidas o conexiones con otras calles. Los valo- } \\
\text { res dependen de la dominancia de las calles } \\
\text { en buen estado que se encontraron dentro } \\
\text { de la unidad de análisis ( } 100 \%) \text {. }\end{array}$ \\
\hline $\begin{array}{l}\text { Cobertura de } \\
\text { las calles }\end{array}$ & $\begin{array}{l}\text { Impactos térmicos e hídricos; Se- } \\
\text { guridad vial. Regulación de conta- } \\
\text { minantes. }\end{array}$ & $\begin{array}{l}\text { Se asignó mayor calidad ambiental a la co- } \\
\text { bertura de las calles con tierra debido a su } \\
\text { aporte en la regulación hídrica y térmica, } \\
\text { mientras que la menor calidad está dada por } \\
\text { calles asfaltadas debido a la ausencia de in- } \\
\text { filtración de agua, aumento de temperatura y } \\
\text { propensión a efecto invernadero. Los valores } \\
\text { dependen de la dominancia de la cobertura } \\
(60 \%) \text {. }\end{array}$ \\
\hline $\begin{array}{l}\text { Basura en las } \\
\text { calles }\end{array}$ & $\begin{array}{l}\text { Insuficiente educación y conscien- } \\
\text { cia ambiental; inadecuado man- } \\
\text { tenimiento urbano; insalubridad; } \\
\text { disminución estética. }\end{array}$ & $\begin{array}{l}\text { La mayor calidad está dada por la ausencia } \\
\text { de algún objeto (residuo) dispuesto en la } \\
\text { calle, mientras que la menor calidad es se- } \\
\text { ñalada por un número mayor a } 40 \text { residuos. } \\
\text { Los registros contemplan por igual el tipo y } \\
\text { tamaño de los residuos. }\end{array}$ \\
\hline $\begin{array}{l}\text { Tipo de } \\
\text { basura en las } \\
\text { calles }\end{array}$ & $\begin{array}{l}\text { Contribuye a la generación de ele- } \\
\text { mentos tóxicos al suelo y a la at- } \\
\text { mósfera; favorece el aumento de } \\
\text { la temperatura; atracción de fauna } \\
\text { nociva. }\end{array}$ & $\begin{array}{l}\text { Se asignó mayor calidad ambiental a la au- } \\
\text { sencia de basura en las calles, mientras que } \\
\text { la menor calidad está dada por la presencia } \\
\text { de residuos plásticos debido a la generación } \\
\text { de elementos tóxicos, poca eficiencia de } \\
\text { reciclaje y contribución al incremento de } \\
\text { temperatura. El registro se fundamentó por la } \\
\text { dominancia del residuo }(60 \%) \text {. }\end{array}$ \\
\hline $\begin{array}{l}\text { Olor de los } \\
\text { depósitos } \\
\text { ilegales de } \\
\text { basura }\end{array}$ & $\begin{array}{l}\text { Insalubridad; disminución del } \\
\text { atractivo estético }\end{array}$ & $\begin{array}{l}\text { Se valoró con mayor calidad a los depósitos } \\
\text { de basura que no despidieron olores en un } \\
\text { rango de } 3 \text { metros de distancia, mientras que } \\
\text { la menor calidad ambiental se presentó en } \\
\text { los depósitos que despidieron malos olores } \\
\text { a } 10 \text { metros de distancia. Este valor refiere al } \\
\text { promedio de las observaciones en los depó- } \\
\text { sitos ilegales de basura con una duración de } \\
3 \text { minutos }\end{array}$ \\
\hline $\begin{array}{l}\text { Fauna } \\
\text { nociva en } \\
\text { los depósitos } \\
\text { de basura } \\
\text { (ilegales) }\end{array}$ & $\begin{array}{l}\text { Insalubridad; Susceptibilidad socio- } \\
\text { ambiental; Seguridad vial. }\end{array}$ & $\begin{array}{l}\text { Se asignó mayor calidad a la ausencia de } \\
\text { fauna nociva, mientras que la menor cali- } \\
\text { dad fue señalada por la concentración de } \\
\text { todas las especies valoradas (perros, gatos, } \\
\text { roedores e insectos). Este valor refiere a la } \\
\text { observación del depósito con una duración } \\
\text { de } 3 \text { minutos }\end{array}$ \\
\hline
\end{tabular}

Fuente: Elaboración propia en base a los resultados del cuestionario piloto sobre calidad ambiental urbana. 
Cuadro $N^{\circ} 3$

Variables ambientales en la temática del aire (C) utilizadas en el ICAU, 2013

\begin{tabular}{|c|c|c|}
\hline Variable & Descriptor de la variable & Forma del rango de registro \\
\hline $\begin{array}{l}\text { Fuentes } \\
\text { contaminantes }\end{array}$ & $\begin{array}{l}\text { Insalubridad; ausencia o insufi- } \\
\text { ciencia de mantenimiento; Ame- } \\
\text { nazas ambientales }\end{array}$ & $\begin{array}{l}\text { Se valoró con mayor calidad a las unida- } \\
\text { des que no presentaron emisiones conta- } \\
\text { minantes, mientras que la menor calidad } \\
\text { fue registrada por la intensa dinámica } \\
\text { vehicular debido a sus efectos agrestes al } \\
\text { entorno inmediato. La cobertura respon- } \\
\text { de a la dominancia visual del } 60 \% \text {. }\end{array}$ \\
\hline $\begin{array}{l}\text { Topes en las } \\
\text { calles (reductores } \\
\text { de velocidad } \\
\text { vehicular) }\end{array}$ & $\begin{array}{l}\text { Seguridad vial; Tránsito peatonal } \\
\text { y automovilístico. }\end{array}$ & $\begin{array}{l}\text { Se valora con mayor calidad ambiental } \\
\text { a las unidades de análisis con menor } \\
\text { cantidad de topes, pero la menor calidad } \\
\text { es indicada por un número mayor a } 7 \text { to- } \\
\text { pes, esto refiere a una mayor descarga de } \\
\text { emisiones contaminantes que provoca el } \\
\text { cambiar a marchas altas por la acción de } \\
\text { acelerar y desacelerar. }\end{array}$ \\
\hline $\begin{array}{l}\text { Contaminantes en } \\
\text { el aire }\end{array}$ & $\begin{array}{l}\text { Insalubridad; efectos negativos } \\
\text { en los sistemas vegetales; dismi- } \\
\text { nución del atractivo urbano; in- } \\
\text { suficiente consciencia ambiental; } \\
\text { aumento de temperatura. }\end{array}$ & $\begin{array}{l}\text { La mayor calidad es registrada por un } \\
\text { cielo con una tonalidad muy clara, } \\
\text { mientras que la menor calidad está dada } \\
\text { por una tonalidad gris obscura, la cual } \\
\text { es un indicativo de la presencia y con- } \\
\text { centración de partículas contaminantes. } \\
\text { La nubosidad queda descartada en el re- } \\
\text { gistro. Además, se utilizó una paleta con } \\
\text { cinco tonalidades a fin de que la valora- } \\
\text { ción presentara mayor exactitud. }\end{array}$ \\
\hline Temperatura & $\begin{array}{l}\text { Energía calorífica; transferencia } \\
\text { de energía. }\end{array}$ & $\begin{array}{l}\text { Se asigna mayor calidad ambiental a los } \\
\text { valores de temperatura templada, la cual } \\
\text { beneficia las actividades humanas y bio- } \\
\text { lógicas. Además, presenta relación con } \\
\text { la mitigación de islas de calor. Los regis- } \\
\text { tros resultan del promedio de tres puntos } \\
\text { de observación y la escala se realizó con } \\
\text { ayuda de un termómetro. }\end{array}$ \\
\hline Viento & $\begin{array}{l}\text { Agente de transporte; disminuye } \\
\text { temperaturas altas; Disipa emisio- } \\
\text { nes contaminantes }\end{array}$ & $\begin{array}{l}\text { Se valora con mayor calidad a los re- } \\
\text { gistros con brisa ligera, ya que con esa } \\
\text { velocidad del viento se observó que las } \\
\text { emisiones iniciaron su disipación. Los } \\
\text { registros son el promedio de tres puntos } \\
\text { de observación, mismos que se ayudó de } \\
\text { un anemómetro. Los rangos fueron adap- } \\
\text { tados de la escala estándar de Beaufort. }\end{array}$ \\
\hline
\end{tabular}

Fuente: Elaboración propia en base a los resultados del cuestionario piloto sobre calidad ambiental urbana.

Los registros de la valoración visual de cada una de las variables del cuestionario fueron diseñados con opción múltiple, donde la estratificación va del 1 al 5, siendo 1 el nivel de más alta calidad ambiental y 5 la menor calidad ambiental (Cuadro $N^{\circ} 4$ ). De forma general, se levantaron dos cuestionarios por AGEB (uno por la mañana de 10:00 
a 13:00 hrs, y otro por la tarde de 16:00 a 19:00 hrs) en tres periodos de trabajo; 1 er y 2 do periodo en el año 2012, corresponden a enero-junio y julio-diciembre respectivamente, mientras que el tercer periodo fue de enero-junio del 2013. En total se obtuvieron 2.400 cuestionarios (en un periodo de 18 meses), equivalente a seis cuestionarios en cada una de las 304 AGEB que constituye el AUMQ.

Cuadro $\mathrm{N}^{\circ} 4$

Variables y rangos utilizados en la valoración visual de la calidad ambiental urbana, 2012-2013

\begin{tabular}{|c|c|c|c|c|c|}
\hline \multirow{2}{*}{ *Variables ambientales } & \multicolumn{5}{|c|}{ Niveles de registro / Rangos de registro } \\
\hline & 1 & 2 & 3 & 4 & 5 \\
\hline A-1. Elementos hídricos & $>6$ & 3 a 5 & 2 a 4 & 1 & 0 \\
\hline A-2. Fugas de agua & 0 & 1 a 2 & 3 a 4 & 4 a 5 & $>7$ \\
\hline A-3. Servicios de autolavado & 0 & 1 & 2 & 3 & $>4$ \\
\hline $\begin{array}{l}\text { A-4. Alcantarillas y bocas de } \\
\text { tormenta }\end{array}$ & $>9$ & 7 a 9 & 4 a 6 & 1 a 3 & 0 \\
\hline $\begin{array}{l}\text { A-5. Color del agua (elementos } \\
\text { hídricos) }\end{array}$ & Clara & Amarilla & Blanca & Café & Negro \\
\hline $\begin{array}{l}\text { A-6. Olor del agua (elementos } \\
\text { hídricos) distancia en metros }(\mathrm{m})\end{array}$ & 5 & 10 & 15 & 20 & 25 \\
\hline $\begin{array}{l}\text { A-7. Basura en el agua } \\
\text { (elementos hídricos) }\end{array}$ & 0 & $1-20$ & $11-30$ & $21-40$ & $>50$ \\
\hline $\begin{array}{l}\text { A-8. Fauna nociva (elementos } \\
\text { hídricos) }\end{array}$ & 0 & $1-3$ & $4-6$ & $7-9$ & $>10$ \\
\hline B-1. Pendiente del terreno (\%) & $<5$ & $6-10$ & $11-15$ & $16-20$ & $>21$ \\
\hline B-2. Vegetación arbórea & $>40$ & $41-31$ & $30-16$ & $15-1$ & 0 \\
\hline $\begin{array}{l}\text { B-3. Depósito de basura en las } \\
\text { calles (legal) }\end{array}$ & $>20$ & 15 & 10 & 5 & 0 \\
\hline $\begin{array}{l}\text { B-4. Depósito de basura en las } \\
\text { calles (ilegal) }\end{array}$ & 0 & 1 & 2 & 3 & $<4$ \\
\hline B-5. Parques y jardines & $>4$ & 3 & 2 & 1 & 0 \\
\hline B-6. Cobertura del suelo urbano & $\begin{array}{l}\text { Área } \\
\text { verde }\end{array}$ & Habitacional & Comercial & Mixto & Industrial \\
\hline B-7. Vegetación arbórea dañada & 0 & $1-15$ & $16-25$ & $26-35$ & $>36$ \\
\hline B-8. Condición de las calles & Muy bien & Bien & Regular & Mal & Muy mal \\
\hline B-9. Funcionalidad de las calles & Muy bien & Bien & Regular & Mal & Muy mal \\
\hline B-10. Cobertura de las calles & Tierra & Empedrado & Adoquín & Chapopote & Asfalto \\
\hline B-11. Basura en las calles & 0 & $1-10$ & $11-20$ & $21-39$ & $<40$ \\
\hline $\begin{array}{l}\text { B-12. Tipo de basura en las } \\
\text { calles, distancia en metros }(\mathrm{m}) \text {. }\end{array}$ & $\begin{array}{r}\text { Sin } \\
\text { basura }\end{array}$ & Papel & Madera & Metal & Plástico \\
\hline $\begin{array}{l}\text { B-13. Olor (depósitos ilegales } \\
\text { de basura) }\end{array}$ & 3 & 5 & 7 & 9 & 10 \\
\hline $\begin{array}{l}\text { B-14. Fauna nociva (depósitos } \\
\text { ilegales de basura) }\end{array}$ & Sin fauna & $\begin{array}{r}\text { Perros y } \\
\text { gatos }\end{array}$ & Roedores & Insectos & $\begin{array}{r}\text { Todos los } \\
\text { anteriores }\end{array}$ \\
\hline C-1. Fuentes contaminantes & $\begin{array}{r}\text { Sin } \\
\text { emisiones }\end{array}$ & Habitacional & Comercial & Industrial & Automóvil \\
\hline
\end{tabular}


Continuación Cuadro $N^{\circ} 4$

\begin{tabular}{|c|c|c|c|c|c|}
\hline \multirow{2}{*}{ *Variables ambientales } & \multicolumn{5}{|c|}{ Niveles de registro / Rangos de registro } \\
\hline & 1 & 2 & 3 & 4 & 5 \\
\hline $\begin{array}{l}\text { C- } 2 \text {. Topes en las calles } \\
\text { (reductores de velocidad } \\
\text { vehicular) }\end{array}$ & 0 & $1-2$ & $3-4$ & $5-6$ & $>7$ \\
\hline $\begin{array}{l}\text { C-3. Contaminantes en el aire } \\
\text { (tonalidad) }\end{array}$ & $\begin{array}{l}\text { Muy } \\
\text { claro }\end{array}$ & Claro & $\begin{array}{r}\text { Ligeramente } \\
\text { opaca }\end{array}$ & Gris & $\begin{array}{r}\text { Gris } \\
\text { oscuro }\end{array}$ \\
\hline $\begin{array}{l}\text { C-4. Temperatura (en grados } \\
\text { Celsius }{ }^{\circ} \mathrm{C} \text { ) }\end{array}$ & $\begin{array}{r}\text { Templada } \\
(15-19)\end{array}$ & $\begin{array}{r}\text { Poco calu- } \\
\text { roso } \\
(20-23)\end{array}$ & $\begin{array}{r}\text { Caluroso } \\
(24-27)\end{array}$ & $\begin{array}{r}\text { Muy calu- } \\
\text { roso } \\
(28-31)\end{array}$ & $\begin{array}{r}\text { Extremo } \\
\text { caluroso } \\
\quad(>32)\end{array}$ \\
\hline C-5. Viento & $\begin{array}{r}\text { Brisa } \\
\text { ligera }\end{array}$ & $\begin{array}{r}\text { Brisa mode- } \\
\text { rada }\end{array}$ & Brisa fresca & Brisa fuerte & $\begin{array}{l}\text { Viento } \\
\text { fuerte }\end{array}$ \\
\hline
\end{tabular}

Fuente: Elaboración propia. ${ }^{*}$ Grupos temáticos: A=Agua; B=Suelo; C=Aire.

Con la información resultante de los cuestionarios se desarrollaron las base de datos por temática (agua, suelo y aire), mismas que fueron integradas a un Sistema de Información Geográfico (SIG). En el SIG los datos se transformaron en vectores a través de layers de puntos; cada punto contiene la respuesta de la valoración visual (del 1 al 5). Después, los datos vectoriales fueron convertidos a dato raster mediante el método de interpolación de distancia inversa (IDW), el cual generó la continuidad espacial mediante la proximidad del valor (1 al 5) respecto al punto más cercano o viceversa.

Las capas resultantes de la interpolación fueron correlacionadas entre sí utilizando álgebra de mapas con base en la siguiente expresión:

$$
\begin{gathered}
I C A U=\sum_{i=1}^{3} N i=N 1+N 2+N 3 \\
N 1=\text { Agua }=\sum_{i=1}^{1} V v ; \quad N 2=\text { Suelo }=\sum_{i=1}^{1} V v ; \quad N 3=\text { Aire }=\sum_{i=1}^{1} V v
\end{gathered}
$$

Donde, ICAU es el índice de calidad ambiental urbana; $\mathrm{Ni}$ es el grupo de variables ambientales (agua, suelo y aire); $v v$ es la valoración visual de cada una de las variables ambientales.

La correlación permitió obtener la unidimensionalidad de cada temática, a la vez de reconocer aquellos lugares del área urbana del municipio de Querétaro donde se pre- senta una menor o mayor calidad ambiental urbana.

\section{Tercera fase. Definición de clústers} espaciales y producción cartográfica

En primera instancia se identificaron los clústers espaciales resultante de la representación del ICAU. Asimismo, fueron determinados por aquellas concentraciones derivadas de los niveles del ICAU, donde se destacó para su representación aquellos grupos que presentaron los sitios prioritarios de atención ambiental, sean los casos de nivel medio, alto y muy alto. Por otra parte, la representación de clúster proporcionó la información faltante a fin de realizar la producción cartográfica. Para lograr la cartografía fue necesaria la inclusión de variables en formato vectorial (curvas de nivel, límites administrativos, ríos y cuerpos de agua). Asimismo, se estableció una plataforma en el Sistema de Información Geográfico que contiene la información base, los resultados del ICAU y la producción cartográfica. Esta herramienta facilitó la manipulación de la gran cantidad de datos y productos generados del ICAU durante los dos años de trabajo.

\section{Calidad ambiental urbana en el AUMQ: agua, suelo y aire}

A fin de responder a la primera interrogante planteada en este trabajo, se exponen a 
continuación los resultados del índice de calidad ambiental urbana (ICAU) producto de la valoración visual de los elementos de agua, suelo y aire del entorno de cada AGEB.

Con base en el grupo temático del agua, la Figura $N^{\circ}$ 3-A muestra la escasez de ríos y cuerpos de agua, así como una baja calidad debido al transporte de agua residual, basura, olores intensos y fauna nociva que demuestran la falta de educación e información ambiental, así como relaciones de poder, omisiones, permisos o responsabilidades dife- renciadas. También se identificaron deficiencias en el sistema de alcantarillado. En suma, se observaron focos de infección y riesgo a inundaciones, especialmente en el centro y norte del AUMQ. Un rasgo común en este grupo temático, fue la constante identificación de desperdicio de agua mediante fugas y servicios de autolavado, este último además se relaciona con la disposición de residuos tóxicos directos al drenaje que pudiera influir en la calidad y suministro del agua potable. En este sentido, la calidad ambiental urbana $(\mathrm{CAU})$ del agua se valoró en el rango medio.
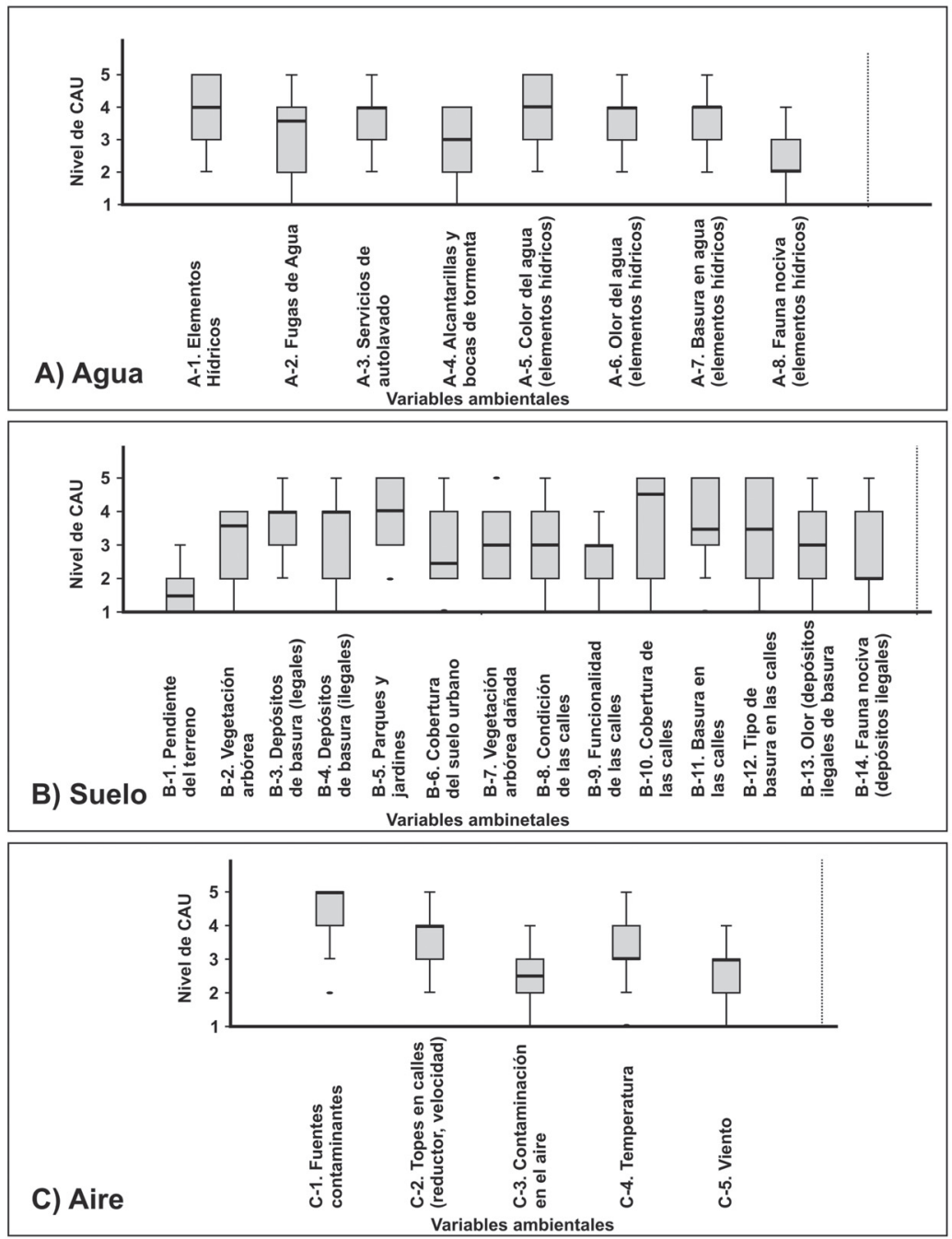

Fuente: Elaboración propia. 
En lo que respecta al grupo temático del suelo, sobresale el predominio de cobertura urbana de tipo habitacional y comercial (mixto) y mínima presencia de parques y jardines, a la vez de la deficiente funcionalidad y calidad de las calles (Figura $N^{\circ} 3-B$ ). Estos elementos y las actividades que reciben (especialmente la dinámica vehicular) influyen en la propagación de $\mathrm{CO}_{2}$ a la atmósfera, incremento de temperatura y disminución de la infiltración de agua, que marca la propensión a efecto invernadero.

Al respecto, existe escasez de vegetación arbórea en la mayoría de las AGEB. Se obtuvo una cantidad de 0.07 árboles por persona en las 304 AGEB que constituyen el AUMQ, mientras que 208 AGEB no cuentan con 50 árboles. En general se contabilizó un promedio de 35 árboles en las AGEB del centro urbano, pero en el sur y norte fue de 20 y 15 árboles respectivamente.

De la misma forma, debido a la valoración visual de gran cantidad de basura (predominio de plásticos) en las calles, la mayoría de las AGEB fueron señaladas con baja CAU, a excepción de la zona centro, donde se valoró con calidad alta. En el centro urbano la basura fue apenas apreciable, mientras que en el sur, 1 de cada 10 AGEB presentó más de 50 residuos en las calles. En el sector norte se contabilizó hasta 150 residuos en las calles de una sola AGEB. A esta problemática se suma la cantidad de depósitos ilegales de basura, los resultados de la valoración indican al menos un depósito ilegal de basura por AGEB, comúnmente colocado en camellones y/o baldíos. En estos depósitos se detectaron malos olores en un rango de $5 \mathrm{~m}$ de distancia, así como la presencia de fauna nociva, representada por fauna feral como perros, gatos y también roedores; en algunos depósitos se contabilizó hasta 7 especies; en los cuales dominaron los perros. Es así que el grupo temático del suelo se valoró entre los niveles de muy baja y baja CAU.

Para el caso de la CAU del aire, la problemática recae en dos principales fuentes contaminantes; industria y vehículos (particulares) (Figura $\mathrm{N}^{\circ} 3-\mathrm{C}$ ). Con base en la valoración visual que se realizó en la mañana, se observó una tonalidad en el cielo entre opaca a ligeramente gris, mientras que en la tarde se observó una tonalidad de clara a muy clara. Esta situación presenta relación con la temperatura y el viento, pues en la mañana se valoró la temperatura entre Poco Caluroso a Muy Caluroso $\left(20^{\circ} \mathrm{C}\right.$ a $\left.31^{\circ} \mathrm{C}\right)$, mientras que la valoración del viento fluctuó entre Calmo y Brisa Moderada. Por la tarde la temperatura se mantuvo en el rango de Caluroso, pero el viento osciló entre Brisa a Brisa Muy Fuerte.

Esto quiere decir que por la mañana se percibió una concentración de partículas contaminantes y por la tarde la dispersión de ellas. Adicional a este tema, cabe señalar que se obtuvo un promedio de 8 topes (reductores de velocidad) por AGEB, que en relación a la deficiente funcionalidad de las calles y la elevada temperatura se favorece la concentración de emisiones vehiculares contaminantes. En suma, la CAU del aire exhibió un nivel medio y alto, de nueva cuenta se señala la propensión a efecto invernadero.

De forma general, la Figura $\mathrm{N}^{\circ} 4$ (secciones $\mathrm{A}$ y B) muestra que la distribución de la CAU del agua y suelo presentan niveles relativamente homogéneos en el centro urbano, pero la calidad disminuye conforme se alejan del mismo, especialmente en el sector 5 . Por su parte, el impacto ambiental en el aire se observa en menor extensión, sea el caso de las zonas contiguas a las zonas industriales y el centro urbano (Figura $N^{\circ} 4$, sección D).

En la Figura $N^{\circ} 4$, sección $D$, se observa que el sector 1 y 2 presentan una CAU de nivel medio, aunque se valoraron zonas con baja calidad debido a la presencia de basura en las calles, contaminación atmosférica (intenso tráfico vehicular) y fugas de agua. El nivel medio de esos sectores presenta relación con la cobertura urbana, representada por comercios y servicios (central de autobuses, seguridad pública y de salud, edificios administrativos y económicos), además cuenta con una franja natural que funciona como amortiguamiento urbano y regulador climático establecido por el Parque Natural El Cimatario. Para el caso del sector 5, la valoración cambió significativamente, pues la CAU se valoró en un nivel bajo, misma que se ha venido mencionando.

Con base en los argumentos planteados hasta el momento, la respuesta a la segun- 
da interrogante está dada por el sector 1 (el norte del $A \cup M Q)$, específicamente en las temáticas de suelo (exceso de basura) y aire (contaminación atmosférica). Además, es en ese sector donde se llevan a cabo los proce- sos actuales más evidentes de cambio de uso de suelo con formas y flujos diversos, a la par de la expansión física, y esta a su vez en la deficiente calidad ambiental y calidad de vida de las personas del AUMQ.

Figura $\mathrm{N}^{\circ} 4$

Distribución de la calidad ambiental urbana establecida por grupo temático: agua, suelo y aire
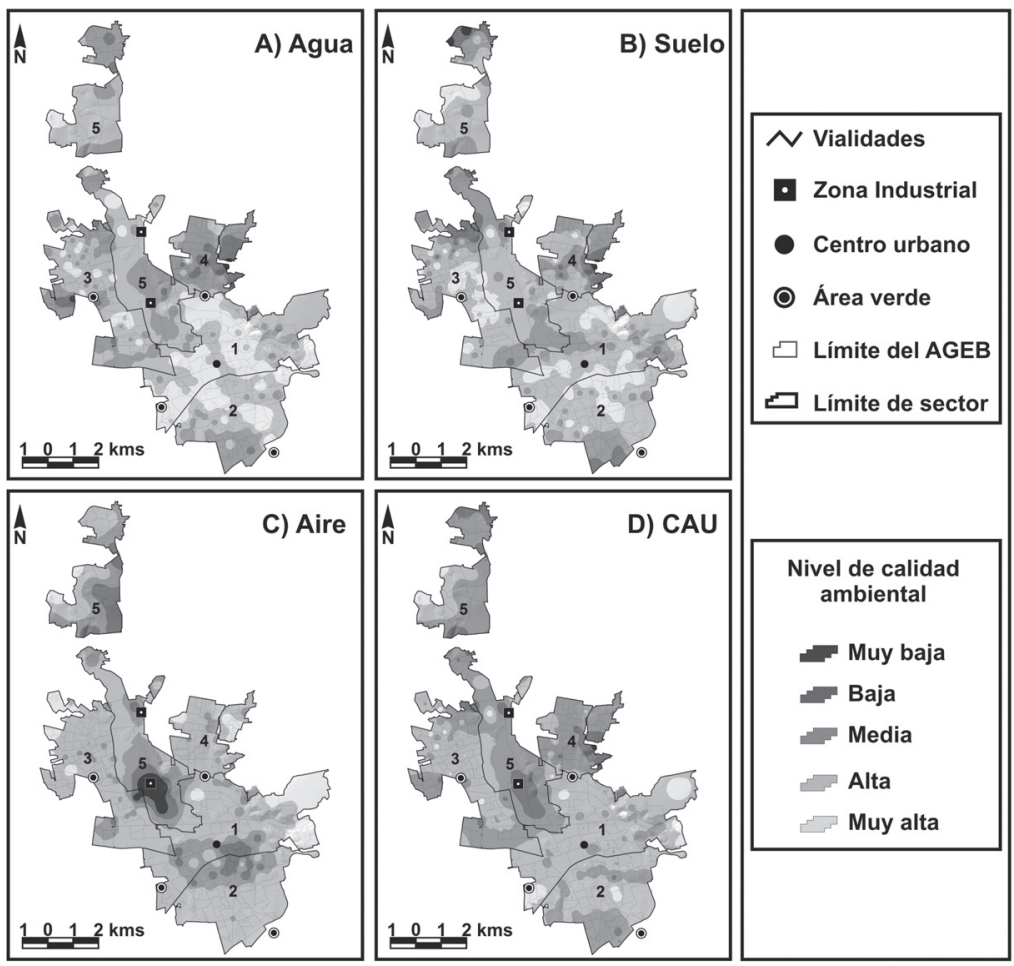

Fuente: Elaboración propia.

Con base en la Figura $\mathrm{N}^{\circ} 5$ se responde la tercera interrogante del trabajo, pues se observa que las zonas prioritarias se localizan en el sector 5, al norte del AUMQ, establecidas por clústers espaciales de gran tamaño (I, II y IV). Aunque también se detectaron clúster de menor tamaño en el este y sur del AUMQ (IV y $\mathrm{V})$. Los sectores prioritarios de atención se encuentran contiguos a las zonas industriales y en la periferia urbana, estos elementos contestan la hipótesis planteada, ya que se confirma que la calidad ambiental urbana disminuye conforme se aleja del centro urbano en dirección del crecimiento y expansión urbana.

En este sentido, los clústers acentúan las diferencias de la calidad ambiental urbana en el AUMQ al año 2013. Al sumar los clústers, la calidad ambiental urbana fue considerada en el nivel medio, eso quiere decir que existe una importante presencia de basura en las calles, contaminación atmosférica, desperdicio de agua y vialidades en malas condiciones (Figura $N^{\circ}$ 6). Así también, los clúster demostraron un caso en particular, el exceso de fauna feral (principalmente perros), con un promedio de 4 perros callejeros por AGEB. Pareciera que este argumento sale del planteamiento del trabajo, pero es un indicativo de la falta de educación y consciencia ambiental, a la vez del poco o nulo conocimiento o atención sobre los elementos perjudiciales al ambiente. 
Figura $\mathrm{N}^{\circ} 5$

Calidad ambiental urbana y clústers espaciales en el AUMQ, 2013
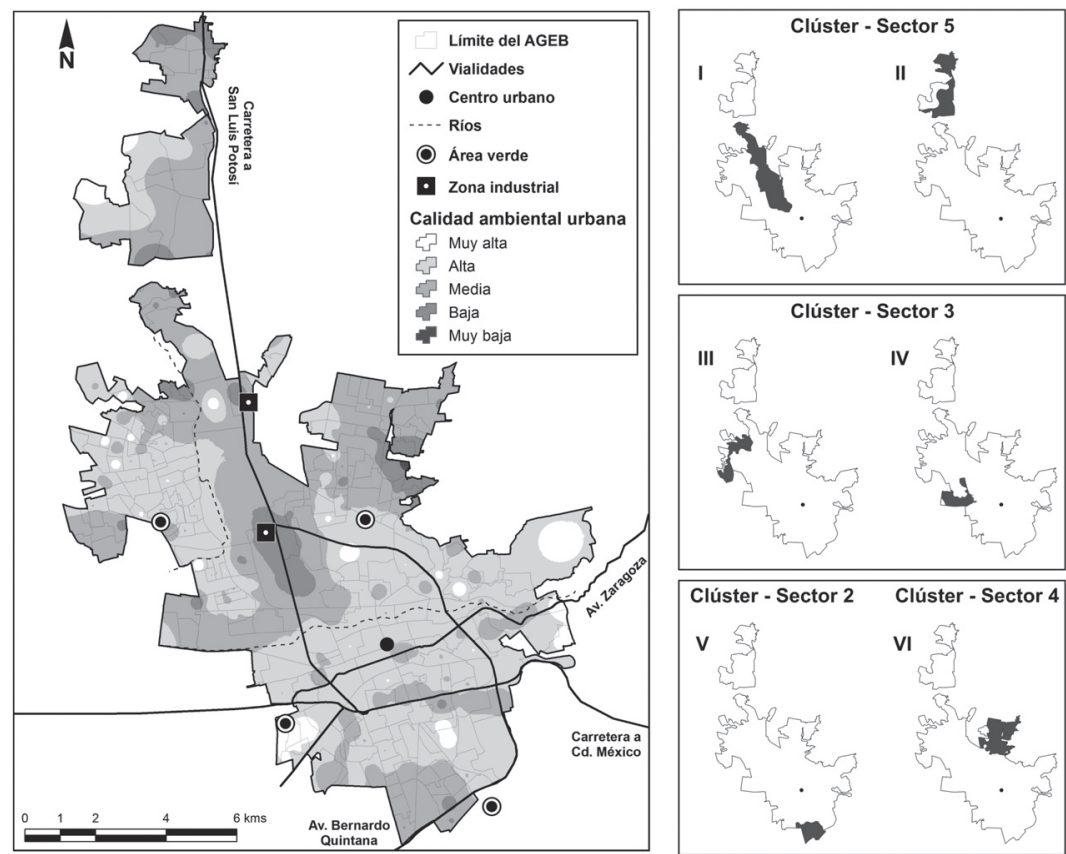

Fuente: Elaboración propia.

Figura $\mathrm{N}^{\circ} 6$

Elementos perjudiciales de la calidad ambiental en el AUMQ

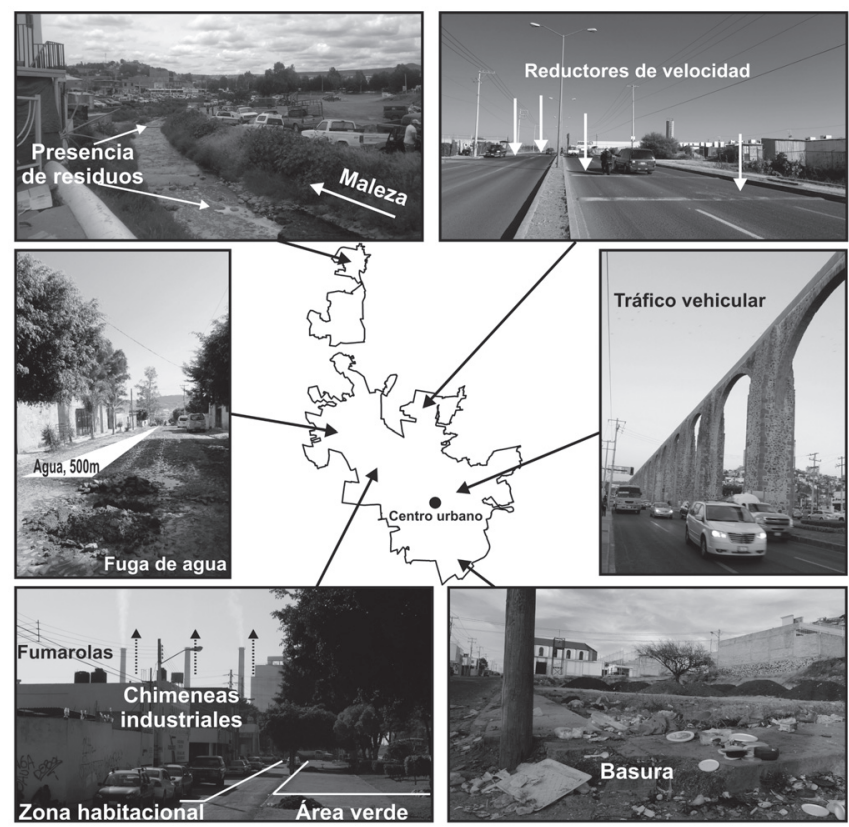

Fuente: Elaboración propia. 


\section{La compleja sencillez de valorar el entorno urbano}

La valoración visual urbana no es un tema nuevo, Lynch (1960) planteaba a la imagen urbana como un sistema de variables objetivas y subjetivas que intervienen en la calidad ambiental y calidad de vida de las personas. Sin embargo, en las últimas décadas se han realizado esfuerzos por integrar la valoración visual en políticas urbanas, es ahí donde los planteamientos actuales se han dirigido, sea para la propia planeación urbana, estrategias de desarrollo ambiental o para mitigar injusticias ambientales.

A pesar de los esfuerzos por valorar el entorno urbano de forma subjetiva, no se ha logrado alcanzar los objetivos político-ambientales esperados, especialmente en ciudades medias (de reconfiguraciones territoriales a gran velocidad derivado de un intenso proceso urbano), aun cuando se ha comprobado que este tipo de técnicas reduce costos, otorgan un visión aproximada de la realidad, genera conocimiento sobre el ambiente y permite diseñar estrategias socioambientales (Santos \& Pinto, 2010; Briceño et al., 2011). El punto crítico sigue siendo el desconocimiento sobre el uso y manejo que otorga la propia valoración visual del ambiente, ya que la subjetividad con que se evalúan variables ambientales conlleva a opiniones encontradas y dirigidas a la desacreditación de la técnica. No obstante, la subjetividad de un registro derivado de la valoración visual ha sido validada y aceptada, así como complementaria en estudios de planeación urbano-ambiental (Briceño et al., 2011; Milroy et al., 2001).

Es una realidad que el uso de técnicas e instrumentos cuasi exactos para evaluar la calidad ambiental (estudios sobre contaminación) es la primera opción en los estudios urbano-ambientales (establecidos por las normas oficiales de cada país), pero esos estudios suelen ser costosos y pocas personas pueden acceder a ellos, a la vez que la información y resultados suelen ser interpretados por expertos con una carga significativa de tecnicismos; los métodos y análisis de carácter nomotético continúan sobresaliendo en la toma de decisiones respecto a los métodos ideográficos, de ahí que la subjetividad se cuantificó. En este trabajo se observó que la calidad ambiental depende de una serie repetitiva de variables interconectadas que promueven la reconfiguración del entorno urbano y complejizan la valoración dada su dinámica (intensidad y magnitud). De esta manera, es que al integrar elementos cuantitativos a la evaluación de variables ambientales se pudo simplificar y minimizar abstracciones subjetivas del entorno, a la vez que se formularon nuevos juicios e interconexiones ambientales entre variables concentradas en grupos de agua, suelo y aire a fin de homogenizar criterios que a su vez otorgaron mayor sencillez al levantamiento e interpretación de la valoración ambiental urbana. Por lo tanto, los resultados obtenidos señalan que la compleja sencillez de valorar el entorno urbano no solo trata de visualizar y percibir variables, sino en la forma de reconocer e interpretar cuántas, cuáles y cómo son las variables que contribuyen en el detrimento o beneficio del entorno urbano, permitiendo valorar la totalidad del área urbana con criterios más homogéneos que faciliten la compleja dinámica ambiental y reduzca conjeturas netamente cualitativas o subjetivas, con lo cual la población en general logre comprender los resultados, y no solo desde posturas tecnócratas.

Para el caso específico del presente trabajo, es importante decir que el ICAU al ser construido con variables cualitativas y cuantitativas también queda sujeto a discusiones, supuestos, conjeturas y polémica. Es innegable que la propuesta del ICAU pudiera salir perfecta, de ahí que presento dos puntos negativos que deben señalarse. El primero refiere a las variables ambientales, ya que en los casos específicos del color y olor, la valoración visual estuvo sujeta a una controversia mayor que el resto de las variables, aunque en el caso del color, se pudo reducir el problema con el uso de una paleta de colores. El segundo punto refiere al tiempo de ejecución, pues para tener una aproximación óptima fue necesario de dos años de trabajo y de diversas observaciones, aunque cabe destacar que la disposición de la información y resultados en el SIG reducirá tiempos y costos para estudios futuros. Además, dada la claridad de los resultados (sin quitar el rigor científico) podrán ser comprendidos por la mayoría de las personas. 
En general, la aplicación metodológica derivó en resultados óptimos, pues al corroborarlos en campo, solo 8 AGEB del AUMQ (sector sur) no tuvieron relación con los resultados del ICAU, posterior a su correlación en el SIG. Aun cuando los resultados no presentan una exactitud de alta precisión (indicativo de la normatividad oficial para medir y evaluar la calidad ambiental de diversos países), es complementario a ellos, a la vez que se puede consultar y disponer de la información para ser incorporada en la evaluación, planeación y toma de decisiones.

La dinámica acelerada del proceso urbano del AUMQ pareciera que ha excedido las estrategias y acciones de solución y control ambiental por parte de las autoridades. Por esa razón, se plantea la valoración visual del entorno urbano como un instrumento políticoadministrativo en la evaluación de políticas a fin de reducir o mitigar procesos de deterioro ambiental. Además, los escenarios de financiamiento de esos procesos deben limitar el trasfondo individualista, desinteresado y preocupado solo por la ganancia, pues no solo contribuye a la generación de espacios diferenciados, sino también al propio proceso de fragmentación urbana. Es así que la presente perspectiva socioambiental puede ser incluida en el análisis del proceso de fragmentación urbana, debido a las divisiones generadas de las diferencias de calidad ambiental entre estratos socioeconómicos y las sensaciones escénicas de detrimento ambiental.

\section{Conclusiones}

La presente propuesta del ICAU, señala que la complejidad de las variables ambientales puede ser valorada visualmente y darla a conocer con relativa sencillez a pesar de su complejidad y dinamismo. Cabe señalar que si bien se utilizaron en algunos casos variables subjetivas o técnicas de álgebra de mapas, el aporte radica en la correlación de información física y social (insumos de todo trabajo geográfico) a través de la valoración visual del entorno inmediato de unidades censales. Esta situación permite que se pueda relacionar información ambiental a la par de un censo de población y vivienda, o bien, que sea una alternativa para identificar presiones sobre el ambiente o disminuir costos en operación. Asimismo, se determinarían sitios prioritarios a fin de establecer redes de monitoreo de calidad ambiental mediante instrumentación cuasi exacta o por valoración visual.

Finalmente, se pone en evidencia la realidad urbano-ambiental de una ciudad intermedia en constante evolución, donde la calidad ambiental urbana se encuentra ligada al intenso desarrollo urbano y reconfiguración territorial, estos a su vez en la generación de espacios y representaciones socioambientales diferenciadas, los cuales contribuyen en el proceso de fragmentación urbana. En este sentido, se debe fomentar la construcción de estrategias para reducir emisiones contaminantes, protección y cuidado a los recursos naturales, actividades de reforestación con conocimiento previo (investigación científica y técnica), planeación urbano-ambiental, educación y conciencia ambiental. Asimismo, es importante señalar que lo natural no está peleado con lo artificial, o lo técnico con lo subjetivo, o las actividades del hombre con sus necesidades, sino que deben entenderse como procesos integrales que deben incluir los planes y estrategias de desarrollo urbano a fin de fomentar una mejor calidad de vida a los presentes y futuros residentes de Querétaro.

\section{Referencias bibliográficas}

ARRIAZA, M.; CAÑAS-ORTEGA, J.; CAÑAS-MADUEÑO, J. \& RUIZ-AVILES, P. Assessing the visual quality of rural landscape. Landscape and Urban Planning, 2003, N 69, p. 115-125.

AZÓCAR, G.; HENRÍQUEZ, C.; VALENZUELA, C. y ROMERO, H. Tendencias sociodemográficas y segregación socioespacial en los Ángeles, Chile. Revista de Geografía Norte Grande, 2008, № 41, p. 103-128.

BÄHR, J. \& BORSDORF, A. La ciudad latinoamericana, la construcción de un modelo, vigencia y perspectivas. Urbes, 2005, Vol. 2, $N^{\circ} 2$, p. 207-221.

BALBO, M.; JORDÁN, R. y SIMIONI. La ciudad de la inclusiva. Cuadernos de la CEPAL, 2003, $\mathrm{N}^{\circ}$ 88. Disponible en Internet: 
http://www.eclac.org/publicaciones/ xml/7/14237/lcg2210p.pdf

BERTRAND, C. y BERTRAND, G. Geografía del Medio Ambiente. El sistema GTP: Geosistema, Territorio y Paisaje. Granada: Ediciones Universidad de Granada, 2007.

BOLAY, J.; PEDRAZZINI, Y.; RABINOVICH, A.; CATENAZZI, A. \& GARCÍA, P. Urban environment, spatial fragmentation and social segregation in Latin America: Where does innovation lie? Habitat International, 2005, No29, p. 627-645.

BRICEÑO, A. y GIL, S. Calidad ambiental de la imagen urbana: Sectores La Parroquia, Alto Chama, Carrizal, Los Curos, Zona Industrial y barrios La Candelaria y San Buenaventura de la ciudad de Mérida-Venezuela. Fermentum. Revista Venezolana de Sociología y Antropología, 2003, Vol. 3, № 38, p. 445-485.

BRICEÑO, A.; DE OWEN, C. y CONTRERAS, M. Propuesta de un sistema de indicadores para evaluar la calidad visual del paisaje urbano. Ecodiseño \& Sostenibilidad, 2011, Vol. 3, No 1, p. 65-104.

CABREIRO, S. y RODRÍGUEZ, CH. Ciudad y territorio en clave de paisaje urbano contemporáneo en España y México. Cuadernos de Vivienda y Urbanismo, 2010, Vol. 3, $\mathrm{N}^{\circ} 6$, p. 182-195.

CHUNG, D.; MUDA, A.; CHE, O. \& ABD, L. Resident's perception of the visual quality of on-site wastes storage bins in kuching. Social and Behavioral Sciences, 2012, № 49, p. 227-236.

CONSEJO DE CIENCIA Y TECNOLOGÍA DEL ESTADO DE QUERÉTARO (CONCYTEQ). Ausencia de flora, ideas para alinear el pensamiento con la naturaleza. Cuadernillos del Jardín Botánico. Querétaro: CONCYTEQ, 2007.

GOMES, M. Desigualdade socioambiental no espaço urbano de Guarapuava. $R A^{\prime} E G A$ - O espaço Geográfico em Análise, 2010, № 20, p. 95-105.

DE VRIES, J.; SCHUSTER, M.; PROCEE, P. \& MENGERS, H. Environmental management of small and medium sized cities in Latin America and the Caribbean. Washington: Working paper, Institute for housing and urban development studies, 2001.

FUENTES, C.; IRARRÁZAVAL, F.; ROMERO, H. y SALGADO, M. Comodificación y segregación socioambiental en Peñalolén. Revista Sociedad \& Equidad, 2011, Nº 1, p. 1-8.

GARCíA, P. La lógica de las grandes acciones inmobiliarias en la ciudad de Querétaro. Estudios Demográficos y Urbanos, 1986, Vol. 3, No 3, p. 375-397.

GONZÁLEZ, G. Segregación urbana dirigida y segregación voluntaria: Querétaro, México. En: XXX Simposio de la ICA, Viena, 15-20 de Julio de 2012.

GRIMMOND, S. Urbanization and global environmental change: local effects of urban warming. The Geographical Journal, 2007, № 173, p. 83-88.

GUERRA, R. La valoración de la imagen urbana en la ciudad de Santa Clara. ISLAS, 2001, Vol. 43, No 130, p. 134-142.

HARVEY, D. Justice, Nature and the Geography of difference. New York: Wiley-Blackwell, 1997.

HERNÁNDEZ, G. \& VIEYRA, M. Adaptation strategies in communities under precarious housing: Flooding risks in the peri-urban sector of the city of Morelia, Michoacán, México. Applied Geography, 2012, Nº34, p. 669-679.

HEYNEN, N. Green urban political ecologies: toward a better understanding of innercity environmental change. Environment and Planning, 2006, №38, p. 499-516.

ICAZURIAGA, M. Desarrollo urbano y forma de vida de la clase media en la ciudad de Querétaro. Estudios Demográficos y Urbanos, 1994, Vol. 2, N²6, p. 439-456.

INSTITUTO NACIONAL DE ESTADÍSTICA Y GEOGRAFÍA (INEGI). Censo de Población y Vivienda 2010. Aguascalientes:. Información digital, INEGI, 2010. 
LYIONS, J.; NAVARRO-PÉREZ, S.; COCHRAN, P.; SANTAN, C. \& GUZMÁN-ARROYO, M. Index of biotic integrity based on fish assemblages for the conservation of streams and rivers in West-Central Mexico. Conservation Biology, 1995, Vol. 9, № 3, p. 569-584.

LYNCH, K. The image of the city. Cambridge, Mass.: MIT Press, 1960.

MILROY, C.; BORJA, P.; BARROS, F. \& BARRETO, M. Evaluating Sanitary quality and classifyng urban sectors according to environmental conditions. Environmenta \& Urbanization, 2001, Vol. 13, No 1, p. 235-255.

MONTOYA, A.; PADILLA, R. \& STANFORD, C. Valoración de la Calidad y Fragilidad visual del paisaje en el Valle de Zapotitlán de las Salinas, Puebla (México). Boletín de la A.G.E.N., 2003, №3, p. 123-138.

MUÑOZ, M.; PÉREZ, L.; SANHUEZA, R.; URRUTÍA, R. y ROVIRA, A. Los paisajes del agua en la Cuenca del río Baker: bases conceptuales para su valoración integral. Revista de Geografía Norte Grande, 2006, №36, p. 31-48.

NICHOL, J. \& WONG, M. Modelling urban environmental quality in a tropical city. Landscape and Urban Planning, 2005, № 73, p.49-58.

PACIONE, M. Urban environmental quality and human welling-a social geographical perspective. Landscape and urban planning, 2003, Vol. 65, № 1, p. 19-30.

PROGRAMA DE LAS NACIONES UNIDAS PARA EL MEDIO AMBIENTE (PNUMA). Perspectivas del medio ambiente urbano: GEO Zona Metropolitana Querétaro. Querétaro: PNUMA, 2008.

ROMERO, H.; IRARRÁZAVAL, F.; OPAZO, D.; SALGADO, M. y SMITH, P. Climas urbanos y contaminación atmosférica en Santiago de Chile. EURE, 2010, Vol. 36, N 109, p. 35-62.
ROMERO, H; SALGADO, M. y FUENTES, C. Segregación Socio-Ambiental en espacios intraurbanos de la ciudad de Santiago de Chile. En: AGUILAR, A. y ESCAMILLA, I. (coordinadores). Periurbanización y Sustentabilidad en Grandes Ciudades. México: Cámara de Diputados, Instituto de Geografía-UNAM, CONACYT, Miguel Ángel Porrúa, 2011, p. 55-82.

SANTANA, R.; ESCOBAR, J. y CAPOTE, P. Estimación de un índice de calidad ambiental urbano, a partir de imágenes de satélite. Revista de Geografía Norte Grande, 2010, № 45, p. 77-95.

SANTOS, C. \& PINTO, J. Percepção da qualidade socioambiental da área urbana de Itabaianaise. Mercator-Revista de Geografía da UFC, 2010, Vol. 9, № 18, p. 93-104.

SANTOS, M. Pensando o Espaço do Homem. Sao Paulo: Editora da Universidade de Sao Paulo (Edusp), 2007.

SCHUSTER, M. \& EDELMAN, D. Latin American trends in urban environmental management. Clean Technologies and Environmental Policy, 2003, N 5, p. 50-60.

SMARDON, R.; PALMER, J. \& FELLEMAN, J. Foundation of visual projects analysis. New York: Wiley Ed., 1986.

VÁSQUEZ, A. y SALGADO, M. Desigualdades socioeconómicas y distribución inequitativa de los riesgos ambientales en las comunas de Peñalolén y San Pedro de la Paz. Una perspectiva de justicia ambiental. Revista de Geografía Norte Grande, 2009, № 43, p. 95-110.

YUAN, CH.; LEE, CH.; LIU, S.; YUAN, $\mathrm{CH} . ;$ YANG, H. \& CHEN, CH. Developing strategies for improving urban visual air quality. Aerosol and Air Quality Research, 2002, Vol. 2, No 1, p. 9-22. 